\title{
Dynamic mechanical characterization and modelling of polypropylene based organoclay nanocomposite
}

\author{
Kui Wang ${ }^{1}$, Rodrigue Matadi Boumbimba ${ }^{2}$, Nadia Bahlouli $^{3}$,, Said Ahzi ${ }^{1}$, and René Muller \\ ${ }^{1}$ Qatar Environment and Energy Research Institute, Qatar Foundation, PO Box 5825, Doha, Qatar \\ 2 National Engineering School of Metz, Laboratory of Mechanics, Biomechanics, Polymers and Structures, 1 route d'Ars \\ Laquenexy, 57078 Metz, France \\ ${ }^{3}$ ICUBE Laboratory-CNRS, University of Strasbourg, 2 rue Boussingault, 67000 Strasbourg, France \\ ${ }^{4}$ Laboratoire d'Ingénierie des Polymères pour les Hautes Technologies, ECPM-LIPHT, Université de Strasbourg, 25 rue \\ Becquerel, 67087 Strasbourg Cedex 2, France
}

\begin{abstract}
In order to investigate the dynamic behaviour of polypropylene based organoclay nanocomposite, the polypropylene matrix and a master batch of polypropylene modified anhydrid maleic were mixed by means of melt mixing technique. The experimental characterization was performed by using split Hopkinson pressure bars (SHPB), at different strain rates and temperatures. A significant increase of the yield stress of nanocomposite was shown with the present of organoclay, comparing to neat PP. A three-phase approach based on the micromechanical formulation of the cooperative model is proposed to model the yield behaviour of the polymer nanocomposite. Our proposed approach accounts for strain rate and temperature effects as well as the organoclay exfoliation effect. The predictions of models for the nanocomposite yield behaviour showed a good agreement with experimental data.
\end{abstract}

\section{Introduction}

Polymer based nanocomposite is one of the hottest worldwide research field from the last decades. This is mainly because the introduction of a low amount of nanoparticles can effectively improve the properties of polymer. Among different nanoparticles, montmorillonite clays are frequently used. Although few works were realized on polypropylene (PP) based organoclay nanocomposite, most of them were focused on the processing, thermal and physical characterization. There is no research on the dynamic mechanical behaviour of PP based organoclay nanocomposites. In this paper, the dynamic mechanical behaviour of PP based organoclay nanocomposites was characterized by means of split Hopkinson pressure bars (SHPB). A three-phase model was used to predict the yield behaviour of the nanocomposites.

\section{Material and sample preparation}

Polypropylene (PP Moplen HP500N) matrix was supplied by Basell. The modified montmorillonite masterbatch composed by $50 \mathrm{wt} \%$ of organoclay, $25 \mathrm{wt} \%$ of polypropylene and $25 \mathrm{wt} \%$ of polypropylene-graft-maleic anhydride (pp-g-MA) was also supplied by Basell. The neat PP reinforced with $0.5,1,3,6 \mathrm{wt} \%$ of organoclay was prepared using a mixer (BUSS Knider) at $50 \mathrm{rpm}$ and a mixing temperature of $200^{\circ} \mathrm{C}$. The samples were injectionmoulded at $200^{\circ} \mathrm{C}$. In the following, the composites will be denoted by PP Nanocor X wt\%, where X is the weight fraction of organoclay.
The dispersion of the organoclay in PP matrix was characterized by X-ray diffraction (XRD) and transmission electron microscopy (TEM) in our previous studies [1]. The results show an exfoliated structure for PP Nanocor with $0.5 \mathrm{wt} \%$ organoclay and a partially exfoliated morphology for the organoclay content above $0.5 \mathrm{wt} \%$.

\section{Experimental investigations}

The high rate tests of PP based organoclay nanocomposites were carried up at various strain rates from $360 \mathrm{~s}^{-1}$ to $2400 \mathrm{~s}^{-1}$ as following : Strain rate $1=360 \pm 6.7 \% \mathrm{~s}^{-1}$, Strain rate $2=816 \pm 4.5 \% \mathrm{~s}^{-1}$, Strain rate $3=1450 \pm$ $4.8 \% \mathrm{~s}^{-1}$ and Strain rate $4=2400 \pm 4.2 \% \mathrm{~s}^{-1}$. It should be noted that all the tests were achieved at variation temperatures from $20^{\circ} \mathrm{C}$ to $80^{\circ} \mathrm{C}$. For neat $\mathrm{PP}$ and $\mathrm{PP}$ organoclay nanocomposites, the yield stresses were measured from the maximum stress of stress-strain curves.

\section{Modelling}

Gueguen et al. [2] developed an extended formulation based on Richeton model [3] to describe the yield behaviour of semi crystalline polymers. In this formulation, the semi crystalline polymer is composed by amorphous phase and crystalline phase:

$$
\frac{\sigma_{y}}{T}=\frac{\sigma_{i}(0)-m \cdot T}{T}+\frac{2 k}{V_{M}} \sinh ^{-1}\left(\frac{\dot{\varepsilon}}{\dot{\varepsilon}_{0} \exp \left(-\frac{\Delta H_{M}}{R T}\right)}\right)^{1 / n}
$$

\footnotetext{
${ }^{a}$ Corresponding author: nadia.bahlouli@unistra.fr
} 


$$
\begin{aligned}
\Delta H_{M} & =\frac{\varphi \cdot \Delta H_{c} \cdot \Delta H_{a}}{\Omega \cdot \Delta H_{a}+(1-\Omega) \cdot \Delta H_{c}}+(1-\varphi) \cdot \Delta H_{a} \\
V_{M} & =\frac{\varphi \cdot V_{c} \cdot V_{a}}{\Omega \cdot V_{a}+(1-\Omega) \cdot V_{c}}+(1-\varphi) \cdot V_{a}
\end{aligned}
$$

where $\sigma_{y}$ is the compressive yield stress, $\mathrm{T}$ refers to the absolute temperature, $k$ is the Boltzmann's constant, $\dot{\varepsilon}$ is the test strain rate, $\dot{\varepsilon}_{0}$ is a constant pre-exponential factor. $\Delta H_{M}$ and $V_{M}$ are the effective activation energy and effective activation volume, respectively. These two parameters were obtained from the activation parameters of amorphous phase $\Delta H_{a}, V_{a}$, and of the crystalline phase, $\Delta H_{c}$ and $V_{c}$, following the Takayanagi micromechanical model (Eq. (2)) [4].

Considering that the microstructure of polypropylene based organoclay nanocomposite is composed by three phases: a homogenized semi-crystalline matrix, the nanoclay fillers and the interphase between the matrix and the fillers. The Pukanszky formulation, Eq. (3) is incorporated into Eq. (1) where the interfacial interaction can be quantitatively characterized [5] as described by Eq. (4).

$$
\begin{gathered}
\frac{\sigma_{y, c}}{\sigma_{y, M}}=\frac{1-\varphi_{f}}{1+2.5 \varphi_{f}} \operatorname{Exp}\left(B \varphi_{f}\right) \\
\frac{\sigma_{y, c}}{T}=\left[\frac{1-\varphi_{f}}{1+2.5 \varphi_{f}} \exp \left(B \varphi_{f}\right)\right] \\
\times\left[\frac{\sigma_{i}(0)-m \cdot T}{T}+\frac{2 k}{V_{M}} \sinh ^{-1}\left(\frac{\dot{\varepsilon}}{\dot{\varepsilon}_{0} \exp \left(-\frac{\Delta H_{M}}{R T}\right)}\right)^{1 / n}\right]
\end{gathered}
$$

where $\sigma_{y, c}, \sigma_{y, M}$ are the yield stresses of the nanocomposite and the PP matrix, respectively, $\varphi_{f}$ is the fillers' volume fraction and $\mathrm{B}$ is a parameter characterizing the interfacial interaction, including the interlayer thickness and interfacial strength. For poor interfacial bonding, the particles do not carry any load, so that $\mathrm{B}=0$. $\mathrm{B}$ increases for the low organoclay concentration, however B decreases for high organoclay clay concentration, showing that B can be related with the exfoliation degree. In fact the low organoclay filled polymer generally leads the exfoliation of the organoclay and a great interfacial surface adhesion between the clay and the polymer matrix.

\section{Results and discussion}

Firstly, PP matrix was considered as a two phase material, composed by an amorphous and a crystalline phase. The yield behaviour of neat PP is then described by Gueguen model [2]. For identification the parameters, the experimental data have to be superposed horizontally and vertically in an Eyring plot at a chosen reference temperature to build a mater curve. Once the master curve is built, the parameters of Gueguen model for neat PP can easily be chose. The parameters are listed in Table 1 . The detail have been reported elsewhere [6]. In Fig. 1,
Table 1. Gueguen models parameters for neat PP.

\begin{tabular}{|l|l|}
\hline Parameters & Value \\
\hline $\mathrm{n}$ & 2.3 \\
\hline$\varphi$ & 0.81 \\
\hline$\dot{\varepsilon}_{0}$ & $1.55 \mathrm{E}+16$ \\
\hline$\sigma_{i}(0)(\mathrm{MPa})$ & 80 \\
\hline$m$ & 0.165 \\
\hline$\rho \mathrm{m}\left(\mathrm{g} / \mathrm{cm}^{3}\right)$ & 0.90 \\
\hline Tref $(\mathrm{K})$ & 313 \\
\hline Cristallinity degree $(\%)$ & 35 \\
\hline$\Delta H_{a}(\mathrm{~kJ} / \mathrm{mol})$ & 69.15 \\
\hline$V_{a}$ & $1.17 \mathrm{E}-28$ \\
\hline$\Delta H_{c}(\mathrm{~kJ} / \mathrm{mol})$ & 119.55 \\
\hline$V_{c}$ & $6.57 \mathrm{E}-28$ \\
\hline $\mathrm{V}_{M}\left(\mathrm{~m}^{3}\right)$ & $2.34 \mathrm{E}-28$ \\
\hline$\Delta \mathrm{H}_{M}(\mathrm{~kJ} / \mathrm{mol})$ & 85.50 \\
\hline
\end{tabular}

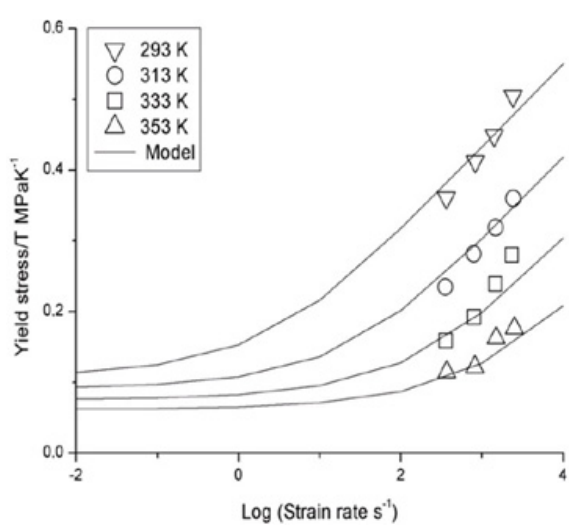

Figure 1. Yield stress/temperature versus strain rate of neat PP.

the predicted results of yield behaviour of neat PP are compared to our experimental results. The cooperative model predictions of the yield stress are in good agreement with the experimental data.

Knowing the parameters for the effective pure PP matrix estimated previously, the yield stress of nanocomposite can be calculated for a given organoclay content, according to Eq. (4), for different values of the parameter B.

According to Aït Hocine et al. [7], the parameter B could be determine by using the following approximation:

$$
B=\frac{1}{\varphi} \ln \left(\frac{\sigma_{y, c}}{\sigma_{y, M}} \frac{1+2.5 \varphi}{1-\varphi}\right) .
$$

Where $\sigma_{y, M}$ and $\sigma_{y, c}$ are the experimentally measured matrix and composite yield stresses, respectively. Using our experimental results for pure PP and PP/organoclay nanocomposites, we can therefore estimate B. Because the parameter $\mathrm{B}$ just depends on the nature of matrix and filler, and process condition. The test temperature and strain rate have no significant effect on the parameter B. For this raison we chose the average values of parameter $\mathrm{B}$ at each organoclay concentration. In order to use parameter B to estimate the extent of exfoliation of PP organoclay nanocomposite, according to the DRX results in our previous studies [1], the highest average $B$ value 71.4 is chosen for fully exfoliation (PP Nanocor $0.5 \%$ ), 

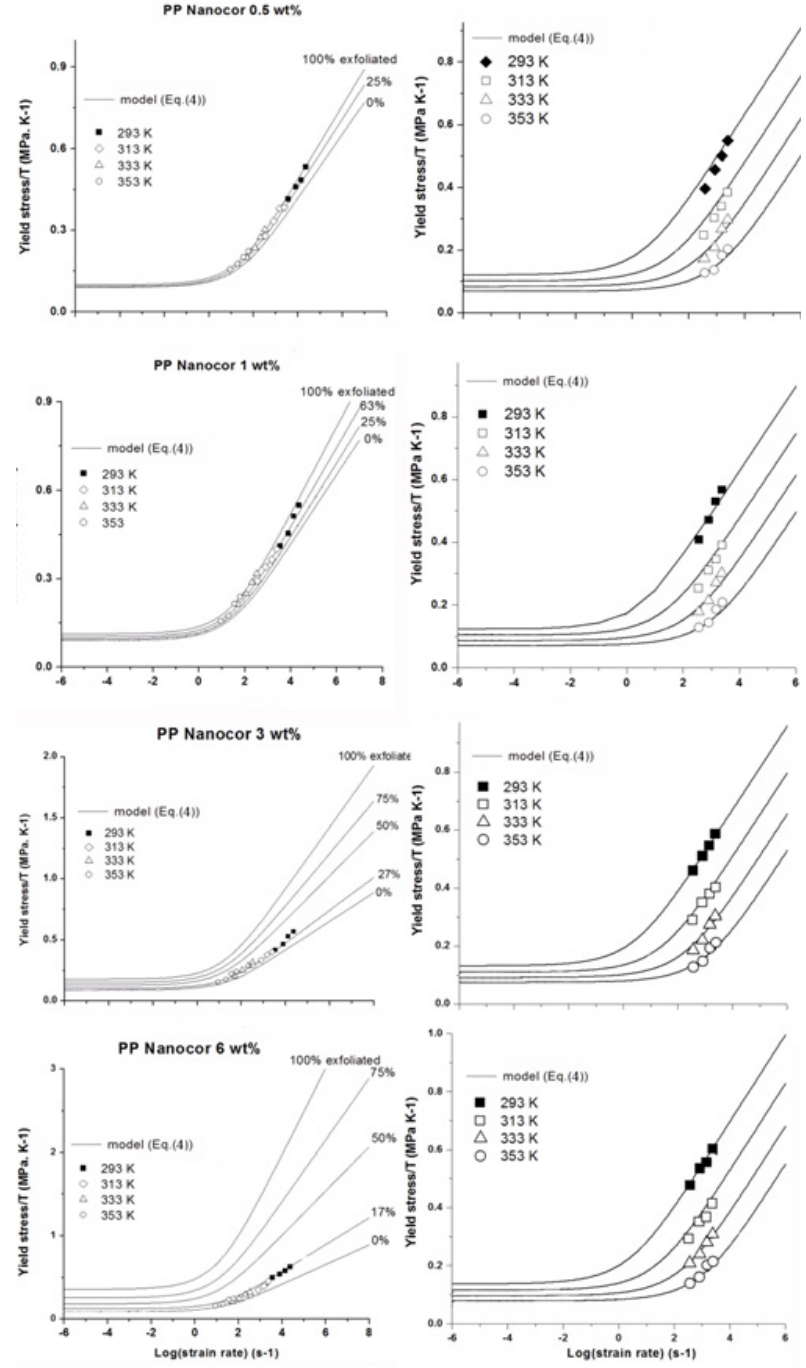

Figure 2. Master curve of PP organoclay nanocomposites build at a reference temperature of $313 \mathrm{~K}$ (Left), Strain rate dependence for the compressive yield stress of PP organoclay nanocomposites models, predictions and experimental data (Right).

other lower average B values are chosen for partially exfoliation with the organoclay content above $0.5 \%$. Then knowing the value of $\mathrm{B}$, the yield stress of the organoclay nanocomposite can be predicted for a given organoclay concentration.

Figure 2 represents the master curves of PP organoclay nanocomposites built at a reference temperature of $313 \mathrm{~K}$ with our three phase model described by Eq. (4) and the comparison between the modelling prediction and experimental investigation of strain rate dependence for the compressive yield stress of PP organoclay nanocomposites. As shown in master curves, the experimental data lies between the two extremes of the extent of exfoliation for all the concentration. In Fig. 2, the three phase model described by Eq. (4), which takes in account the interphase contribution though the parameter $\mathrm{B}$, predicts results that spans from low to high exfoliation degree. Thus, the three phase model yields good agreement with the experimental results for $100 \%, 63 \%, 27 \%$ and $17 \%$ exfoliation for $0.5,1,3$ and $6 \mathrm{wt} \%$ nanocomposites, respectively. These correspond to B values of 71.4, 46.6, 20.4, and 13.1 respectively. In Fig. 2, it can also be noticed that the range of the yield stress between the minimum and the maximum degree of exfoliation increases with increasing organoclay concentration. This observation is caused by the fact that increasing both particle concentration and extent of exfoliation, increases the specific surface area and lead to enhancement of the yield stress. The strain rate dependence for the compressive yield stress of PP organoclay nanocomposites were plotted on the right side of Fig. 2. The three phase model provides an excellent agreement with experimental data for different strain rates and temperatures. This very good agreement obtained with the three phase model allows us to conclude that the yield behaviour of PP organoclay nanocomposite depends heavily on the yield stress of the virgin matrix PP and on the extent of exfoliation. The fact that the three phase model accounts for the degree of exfoliation making a more robust model for the yield behaviour of polymer nanocomposites.

\section{Conclusion}

Dynamic compressive yield behaviour of a melt mixing polypropylene based organoclay nanocomposites has been studied using split Hopkinson pressure bars (SHPB). Experimental results have shown that the yield stress increases with increasing strain rate, organoclay concentration and the extent of exfoliation. However, as expected, the yield stress decreases with increasing temperature. The modified three phase cooperative model was used to predict the yield stress of PP/organoclay nanocomposites. In this three phase model, a parameter $B$ allows for the effect of the extent of exfoliation. It is shown that parameter $B$ increases with the increase of extent of exfoliation and decreases with organoclay concentration. The three phase model gives a fairly good prediction of experimental data within the investigated range, which account for the degree of exfoliation. This is an important factor in the determination of the properties of polymer organoclay nanocomposites. Therefore, we believe that this modified three phase cooperative model is more appropriate for the modelling of the yield behaviour of polymer nanocomposites.

The authors would like to thank the Alsace Region for their financial support. The authors also acknowledge the Fond National de la Recherche (FNR) of Luxembourg for the Ph.D. financial support for K. Wang.

\section{References}

[1] K. Wang, R. M. Boumbimba, N. Bahlouli, S. Ahzi, R. Muller, and M. Bouquey, Journal of Engineering Materials and Technology 134 (1, 010905), 11 (2012).

[2] O. Gueguen, J. Richeton, S. Ahzi, and A. Makradi, Acta Materialia 56, 1650 (2008).

[3] J. Richeton, S. Ahzi, L. Daridon, and Y. Remond, Polymer 46 (16), 6035 (2005). 
[4] M. Takayanagi, Kyushu Univ 23, 1 (1963).

[5] B. Pukánszky Jr, K. Bagdi, Z. Tóvölgyi, J. Varga, L. Botz, S. Hudak, T. Dóczi, and B. Pukánszky, European Polymer Journal 44 (8), 2431 (2008).
[6] R. M. Boumbimba, K. Wang, N. Bahlouli, S. Ahzi, Y. Rémond, and F. Addiego, Mechanics of Materials, submitted (2012).

[7] N. Aït Hocine, P. Médéric, and T. Aubry, Polymer Testing 27 (3), 330 (2008). 